\title{
ECG with Prior Myocardial Infarction Pattern or acute ST-T Pathology is Associated with Death in Critically III COVID-19 Patients
}

Jacob Rosen ( $\nabla$ jacob.rosen@surgsci.uu.se)

Uppsala University: Uppsala Universitet https://orcid.org/0000-0001-9518-5834

Maria Noreland

Uppsala University: Uppsala Universitet

Karl Stattin

Uppsala University: Uppsala Universitet

Miklós Lipcsey

Uppsala University: Uppsala Universitet

Robert Frithiof

Uppsala University: Uppsala Universitet

Andrei Malinovschi

Uppsala University: Uppsala Universitet

Michael Hultström

Uppsala University: Uppsala Universitet

\section{Research}

Keywords: ECG, COVID-19, mortality, cardiac, biomarkers, inflammation, intensive care unit

Posted Date: June 14th, 2021

DOI: https://doi.org/10.21203/rs.3.rs-419853/v2

License: (9) This work is licensed under a Creative Commons Attribution 4.0 International License.

Read Full License 


\section{Abstract}

Background: We investigated the prevalence of ECG abnormalities and their association with mortality, organ dysfunction and cardiac biomarkers in a cohort of COVID-19 patients admitted to the intensive care unit (ICU).

Methods: This cohort study included patients with COVID-19 admitted to the ICU of a tertiary hospital in Sweden. ECG, clinical data and laboratory findings during ICU stay were extracted from medical records and ECGs obtained near ICU admission were reviewed by two independent physicians.

Results: Eighty patients had an acceptable ECG near ICU-admission. In the entire cohort 30-day mortality was $28 \%$. Compared to patients with normal ECG, among whom 30 -day mortality was $16 \%$, patients with ECG fulfilling criteria for prior myocardial infarction had higher mortality, 63\%, odds ratio (OR) 9.61 (95\% confidence interval (Cl) 2.02-55.6) adjusted for Simplified Acute Physiology Score 3 and patients with STT abnormalities had $50 \%$ mortality and OR $6.05(95 \% \mathrm{Cl} 1.82-21.3)$ in univariate analysis. Both prior myocardial infarction pattern and ST-T pathology were associated with need for vasoactive treatment and higher peak plasma levels of troponin-I, NT-pro-BNP (N-terminal pro-Brain Natriuretic Peptide), and lactate during ICU stay compared to patients with normal ECG.

Conclusion: ECG with prior myocardial infarction pattern or acute ST-T pathology at ICU admission is associated with death, need for vasoactive treatment and higher levels of biomarkers of cardiac damage and strain in severely ill COVID-19 patients, and should alert clinicians to a poor prognosis.

Trial registration: ClinicalTrials ID: NCT04316884. Registered 20 March 2020, https://clinicaltrials.gov/ct2/show/NCT04316884.

\section{Introduction}

Although Corona virus disease 2019 (COVID-19) primarily affects the respiratory system and may cause severe pneumonia and hypoxemic respiratory failure[1], other organ systems are also frequently affected, such as the renal[2] and the cardiovascular system[3]. Typical cardiovascular risk factors, such as hypertension, diabetes and cerebrovascular disease are associated with a higher risk of severe disease[4, 5]. Elevated cardiac biomarkers during hospitalization due to COVID-19 are associated with higher risk of severe disease and mortality[6-11]. Proposed mechanisms for cardiac injury include demand ischemia in patients with pre-existing coronary artery stenosis, diffuse myocardial injury due to hypoxemia or arrythmia, Takotsubo syndrome, myocarditis and pulmonary hypertension secondary to adult respiratory distress syndrome (ARDS) or pulmonary embolism[3, 12-14].

The electrocardiogram (ECG) is a readily available, non-invasive, radiation free diagnostic mainstay of cardiac pathology[15] used at some point in nearly all severely ill patients[16]. ECG abnormalities in patients with COVID-19 have been described in small case series early during the pandemic[17-20] and analyses of larger cohorts have found that ECG pathology at hospital admission was associated with 
more severe disease and higher mortality [9, 21-24]. Unfortunately, previous studies have not specifically investigated patients admitted to the intensive care unit (ICU), who have the highest mortality[5]. ECG at ICU admission may differ from ECG at hospital admission and further knowledge of ECG abnormalities at ICU admission may add important diagnostic and prognostic information.

The primary aim of this study was to describe the prevalence of ECG pathology among COVID-19 patients at ICU admission and its association with mortality. We further aimed to compare laboratory findings including cardiac biomarkers in patients with and without ECG pathology.

\section{Methods}

\section{Study design, setting and population}

This study was performed as a subgroup analysis of the PronMed cohort study[25] in patients consecutively admitted to a mixed medical and surgical ICU between March 23 and July 14, 2020 at Uppsala University Hospital, a tertiary care teaching hospital in Sweden. The protocol was approved by the National Ethical Review Agency, Uppsala, Sweden (EPM; 2020 - 01623), and registered at ClinicalTrials (NCT04316884). Written informed consent was obtained from all participants or next of kin if the patient was unable to give consent. STROBE guidelines were followed for reporting.

Patients > 18 years old admitted to the ICU with COVID-19 diagnosis confirmed by positive SARS-CoV-2 reverse transcription polymerase chain reaction tests on naso- or oropharyngeal swabs were eligible for inclusion in this study if they had an ECG recorded within 48 hours prior to, or within 72 hours after ICU admission.

\section{Data collection and ECG interpretation}

Demographic data, medical history, laboratory findings, treatment measures and ECG were extracted from the medical records during ICU stay. Two physicians with profound experience of ECG interpretation (JR, $\mathrm{MN}$ ) analysed the ECGs independently according to pre-specified criteria and recorded findings in a standardized case report form. The physicians were blinded to patient outcomes during ECG interpretation. Discrepancies were resolved by consensus.

ECG data[26] included rhythm, premature atrial and ventricular contractions (PAC and PVC), frontal plane axis, PQ-time, QRS-duration, Bazett-corrected[27] QT-interval (QTc), poor R-wave progression, P-wave pathology, left and right ventricular hypertrophy ( $\mathrm{LVH}$ and $\mathrm{RVH}), \mathrm{S}_{1} \mathrm{Q}_{3} \mathrm{~T}_{3}$ pattern, conduction blocks, STsegment abnormality (depression or elevation), T-wave inversion, right ventricular strain pattern and unspecific repolarization abnormalities (e.g. flat or low T-waves).

We defined two composite ECG patterns to represent chronic and acute cardiac conditions: ECG with prior myocardial infarction (MI) pattern and ECG with ST-T pathology. ECG with prior myocardial infarction (MI) pattern was defined as presence of pathological Q-waves[28] and/or poor precordial R-wave 
progression $[29,30]$ in the absence of criteria for LVH, RVH and conduction blocks. ECG with ST-T pathology was defined as presence of pathological ST-elevation, ST-depression or T-wave inversion[31]. Laboratory data was compared in patients with either composite ECG patterns to those with normal ECG.

\section{Statistical analysis}

All data was analysed using Microsoft Excel (Redmond, WA, USA) and the R package "rcmdr" (Rcmdr: R Commander. R package version 3.6.3). Data were presented as mean and standard deviations (SD) or median and interquartile range (IQR) for normally and non-normally distributed data respectively. Categorical variables were presented as numbers (percentages). Univariate logistic regression was performed to investigate the relationship between ECG pathology and mortality. Multivariate analysis adjusted for SAPS 3 was performed for individual and composite ECG pathology. Normally and nonnormally distributed continuous data was compared using independent t-test and Mann-Whitney U-test respectively and Chi-square or Fischer's exact tests were used to compare categorical data as appropriate. Two-sided p-values $<0.05$ were considered statistically significant. Due to the exploratory nature of this study, we did not adjust for multiple statistical testing.

\section{Results}

\section{Patient characteristics}

Between March 23 and July 14, 2020, 168 patients were admitted to the ICU with confirmed COVID-19, of which 123 patients (76\%) were included in the PronMed cohort. 83 patients had an ECG recorded within 48 hours prior to up to 72 hours following ICU admission. Three patients were excluded due to poor ECG quality, leaving 80 patients ( $65 \%$ of included patients) for final analysis. The mean age was 60.6 (SD 13.6), mean body mass index $30.0 \mathrm{~kg} \mathrm{~m}^{-2}$ (SD 5.9) and 20 patients (25\%) were female (Table 1 ). The most common comorbidities were hypertension (54\%) and diabetes (26\%). Ten patients (13\%) had preexisting ischemic heart disease, 14 patients $(18 \%)$ had atherosclerotic vascular disease and three patients $(4 \%)$ had heart failure. Patients had a mean Simplified Acute Physiology Score (SAPS 3$)^{32}$ of 53 (SD 10) and a median $\mathrm{PaO}_{2} / \mathrm{FiO}_{2}$ ratio of 17.8 (IQR 15.5-23.5) kPa at ICU admission. Patients with an ECG pattern of prior MI and ST-T pathology were older and had higher prevalence of hypertension, diabetes, cardiovascular and vascular disease than patients with normal ECG.

\section{ECG characteristics}

ECG were recorded at median day 0 (IQR -1 to 0 ) of ICU stay. The majority of patients were in sinus rhythm at ICU admission (Table 2) and 51 (64\%) had a normal ECG. The mean heart rate was 89 (SD 17) and 24 patients were tachycardic (defined as a heart rate $\geq 100 \mathrm{~min}^{-1}$ ). Eleven patients (14\%) had an ECG pattern consistent with prior $\mathrm{Ml}$ although only four of these had a prior diagnosis of ischemic heart disease. 17 patients (21\%) had an ECG with ST-T-pathology. Twenty-seven (34\%) patients had a conduction block but LBBB and RBBB were rare. T-wave inversion ( $n=13,16 \%)$ was the most common repolarization abnormalities, whereas ST-depression or ST-elevation were found in six patients (8\%). Although RBBB or $\mathrm{S}_{1} \mathrm{Q}_{3} \mathrm{~T}_{3}$ morphology were noticed in isolation in three patients, there were no patients 
with an ECG compatible with acute right ventricular strain and none of the 9 patients (11\%) who were diagnosed with pulmonary embolism prior to or following ICU admission (Table 1) had ECG characteristics indicative of the diagnosis. 
Table 1

Patient characteristics at baseline and ICU admission.

\begin{tabular}{|c|c|c|c|c|}
\hline & $\begin{array}{l}\text { All patients } \\
(n=80)\end{array}$ & $\begin{array}{l}\text { Normal ECG } \\
(n=51)\end{array}$ & $\begin{array}{l}\text { Prior MI } \\
\text { pattern }(n=11)\end{array}$ & $\begin{array}{l}\text { ST-T pathology } \\
(n=17)\end{array}$ \\
\hline \multicolumn{5}{|l|}{ Baseline characteristics } \\
\hline Age (years) & $61(14)$ & $56(12)$ & $66(11)$ & $71.5(13.3)$ \\
\hline Sex (female) & $20(25)$ & $14(27 \%)$ & $2(18 \%)$ & $6(35 \%)$ \\
\hline Weight (kg) & $89(20)$ & $90(20)$ & $89.8(15.9)$ & $85.3(20.2)$ \\
\hline Length $(\mathrm{cm})$ & $175(9)$ & $175(10)$ & $175(10)$ & $170(7)$ \\
\hline $\mathrm{BMI}\left(\mathrm{kg} \mathrm{m}^{-2}\right)$ & $30(5.9)$ & $29(6)$ & $32.2(5.7)$ & $30.7(6.1)$ \\
\hline \multicolumn{5}{|l|}{ Preexisting comorbidities } \\
\hline Hypertension & $43(54 \%)$ & $25(49 \%)$ & $8(73 \%)$ & $13(76 \%)$ \\
\hline Diabetes Mellitus & $21(26 \%)$ & $10(20 \%)$ & $6(55 \%)$ & $7(41 \%)$ \\
\hline Ischemic heart disease & $10(13 \%)$ & $3(6 \%)$ & $4(36 \%)$ & $3(18 \%)$ \\
\hline Heart failure & $3(4 \%)$ & $1(2 \%)$ & $2(18 \%)$ & $2(12 \%)$ \\
\hline Pulmonary embolism & $1(1 \%)$ & $0(0 \%)$ & $1(9 \%)$ & $1(6 \%)$ \\
\hline Pulmonary hypertension & $0(0 \%)$ & $0(0 \%)$ & $0(0 \%)$ & $0(0 \%)$ \\
\hline Malignant disease & $7(9 \%)$ & $2(4 \%)$ & $0(0 \%)$ & $5(29 \%)$ \\
\hline Liver failure & $1(1 \%)$ & $1(2 \%)$ & $0(0 \%)$ & $0(0 \%)$ \\
\hline Pulmonary disease & $22(28 \%)$ & $16(31 \%)$ & $1(9 \%)$ & $5(29 \%)$ \\
\hline Vessel disease & $14(18 \%)$ & $4(8 \%)$ & $6(55 \%)$ & $4(24 \%)$ \\
\hline \multicolumn{5}{|l|}{ ICU characteristics } \\
\hline $\begin{array}{l}\text { Days with symptoms at ICU- } \\
\text { admission }\end{array}$ & $8.5(5-16)$ & $8.5(5-15)$ & $16(9-18)$ & $7(6-12)$ \\
\hline SAPS 3 & $53(10)$ & $51(8)$ & $54(7)$ & $63(55-70)$ \\
\hline $\begin{array}{l}\text { Average } \mathrm{PaO}_{2} / \mathrm{FiO}_{2} \text { ratio ICU } \\
\text { day } 1\end{array}$ & $\begin{array}{l}17.7(15.5- \\
23.5)\end{array}$ & $\begin{array}{l}19.0(15.7- \\
24.3)\end{array}$ & $\begin{array}{l}16.1(15.1- \\
18.4)\end{array}$ & $\begin{array}{l}16.0(15.1- \\
18.4)\end{array}$ \\
\hline $\begin{array}{l}\text { Pulmonary embolism } \\
\text { diagnosed during ICU stay }\end{array}$ & $9(11 \%)$ & 7 (13\%) & $2(18 \%)$ & $0(0 \%)$ \\
\hline $\begin{array}{l}\text { Data are presented as mean } \\
\text { Intensive care unit. Ml: myo }\end{array}$ & $\begin{array}{l}\text { edian (int } \\
\text { ifarction. }\end{array}$ & $\begin{array}{l}\text { tile range) a } \\
\text { 3: Simplifies }\end{array}$ & $\begin{array}{l}\text { umbers } \\
\text { tte Phys }\end{array}$ & $\begin{array}{l}\text { ges)., ICU: } \\
\text { ore } 3 \text { [32]. }\end{array}$ \\
\hline
\end{tabular}


Table 2. ECG characteristics 48 hours prior to, or 72 hours after, admission to the intensive care unit.

ECG characteristics

Composite EGG patterns

Normal ECG

Prior myocardial infarction

ST-T-pathology

\section{Rhythm}

Sinus rhythm

Heart rate

Atrial fibrillation

SVT

Heart rate (range)

Tachycardia $(\mathrm{HR}>100)$

Bradycardia $(\mathrm{HR}<50)$

Premature contraction

Atrial

Ventricular

ECG measurements

QRS-axis $\left({ }^{\circ}\right)$

Left axis deviation $\left(<-30^{\circ}\right)$

Right axis deviation $\left(>+90^{\circ}\right)$

PR interval (ms)

QRS duration (ms)

QRS > 120 ms n(\%)

QTc (ms)

QTc>500 ms

Conduction blocks

AV-block I, II or III

Intraventricular block

Left hemiblock

Partial RBBB

Partial LBBB

RBBB

LBBB

\section{Morphology}

Early repolarisation

Pathological Q-wave

Poor R-wave progression

$\mathrm{S}_{1} \mathrm{Q}_{3} \mathrm{~T}_{3}$-morphology

Left ventricular hypertrophy

ST-elevation

ST-depression

T-wave inversion

U-wave
All patients $(n=80)$

$51(64 \%)$

$11(14 \%)$

17 (21\%)

$76(95 \%)$

$89(17)$

$3(4 \%)$

(100-178)

$1(1 \%)$

$24(30 \%)$

$1(1.3 \%)$

$4(5 \%)$

$5(6 \%)$

$14(39)$

$7(9 \%)$

$2(3 \%)$

$153(24)$

$91(16)$

$2(3 \%)$

$440(27)$

2 (3\%)

$0(0 \%)$

$14(18 \%)$

5 (6\%)

$4(5 \%)$

2 (3\%)

1 (1\%)

1 (1\%)

2 (3\%)

7 (9\%)

$5(6 \%)$

2 (3\%)

$6(8 \%)$

1 (1\%)

$5(6 \%)$

$13(16 \%)$

$1(1 \%)$ 
Data are presented as mean (standard deviation) or $n(\%)$ if not stated otherwise. Prior myocardial infarction includes ECG with Q-wave and/or poor R-wave progression. ST-Tpathology includes ECG with ST-elevation, ST-depression or T-wave inversion. SVT:

supraventricular tachycardia, QTc: Corrected QT interval according to Bazett. RBBB: Right bundle branch block. LBBB: Left bundle branch block.

Mortality

At 30 days follow-up, 22 patients (28\%) had died. Among patients with normal ECG, 30-day mortality was $16 \%$. Among patients with an ECG consistent with prior MI pattern mortality was $63 \%$ and among patients with ST-T pathology, mortality was $50 \%$. In univariate logistic regression analysis, prior MI pattern, ST-T pathology, PAC and/or PVC, pathological Q-wave, poor R-wave progression, ST-depression and T-wave inversion were associated with higher odds of death (Table 3). In multivariate analysis for the composite ECG-patterns, adjusting for SAPS 3, prior MI pattern was associated with higher odds of death. Kaplan-Meier survival analyses in patients with normal ECG versus patients with either composite ECGpattern (prior MI pattern and ST-T pathology) are presented in Figure 1 and 2.

Table 3. Analysis of odds ratio for death 30 days after admission to the intensive care unit with normal ECG $(n=51)$ as reference. Multivariate analysis performed for composite ECG patterns and adjusted for SAPS 3. 


\begin{tabular}{|c|c|c|c|c|c|c|}
\hline & & & Univariate & alysis & $\begin{array}{l}\text { Multivariat } \\
\text { analysis }\end{array}$ & \\
\hline ECG-abnormalities & $\begin{array}{l}\text { Survived } \\
(\mathrm{n}=58)\end{array}$ & $\begin{array}{l}\text { Died } \\
(\mathrm{n}=22)\end{array}$ & $\begin{array}{l}\text { OR }(95 \% \\
\text { CI })\end{array}$ & $\begin{array}{l}\text { P- } \\
\text { value }\end{array}$ & $\begin{array}{l}\text { OR }(95 \% \\
\text { CI })\end{array}$ & $\begin{array}{l}\mathrm{P}- \\
\text { value }\end{array}$ \\
\hline $\begin{array}{l}\text { Composite } \\
\text { abnormalities } \\
\text { Normal ECG }\end{array}$ & $43(74 \%)$ & $8(36 \%)$ & Ref. & n.a. & Ref. & n.a. \\
\hline Prior MI pattern & $4(7 \%)$ & $7(31 \%)$ & 9.63 (2.38- & 0.002 & 9.61 (2.02- & 0.006 \\
\hline ST-T pathology & $8(14 \%)$ & $9(41 \%)$ & $\begin{array}{l}6.05(1.82- \\
21.3)\end{array}$ & 0.004 & $\begin{array}{l}1.95(0.42- \\
8.52)\end{array}$ & 0.38 \\
\hline $\begin{array}{l}\text { Single } \\
\text { abnormalities }\end{array}$ & & & & & & \\
\hline Heart rate $\left(\min ^{-1}\right)$ & $91(20)$ & $92(21 \%)$ & $\begin{array}{l}1.00(0.98- \\
1.03)\end{array}$ & 0.86 & & \\
\hline QTc (ms) & $441(27)$ & $437(27)$ & 0.99 (0.97- & 0.57 & & \\
\hline $\begin{array}{l}\text { Tachycardia (>100 } \\
\text { min }^{-1} \text { ) }\end{array}$ & $16(28 \%)$ & $8(36 \%)$ & $\begin{array}{l}3.30(0.95- \\
12.5)\end{array}$ & 0.065 & & \\
\hline $\mathrm{PAC}$ and/or PVC & $4(7 \%)$ & $5(23 \%)$ & 7.32 (1.57- & 0.011 & & \\
\hline Conduction block & $21(36 \%)$ & $6(27 \%)$ & $1.18(0.33-$ & 0.79 & & \\
\hline LVH & $3(5 \%)$ & $3(14 \%)$ & $5.50(0.86-$ & 0.059 & & \\
\hline Q-wave & $3(5 \%)$ & $4(18 \%)$ & 7.33 (1.38- & 0.020 & & \\
\hline $\begin{array}{l}\text { Poor R-wave } \\
\text { progression }\end{array}$ & $1(2 \%)$ & $4(18 \%)$ & $\begin{array}{l}22.0 \\
462)\end{array}$ & 0.009 & & \\
\hline ST-depression & $2(3 \%)$ & $3(14 \%)$ & 8.25 (1.19- & 0.033 & & \\
\hline T-wave inversion & $6(10 \%)$ & $7(31 \%)$ & $\begin{array}{l}6.42(1.73- \\
25.4)\end{array}$ & 0.006 & & \\
\hline
\end{tabular}

Data are presented as absolute numbers (percentages) or mean (standard deviation).CI:

Confidence interval. SAPS 3: Simplified Acute Physiology Score ${ }^{32}$. Prior MI (myocardial infarction) pattern includes ECG with $Q$-wave and/or poor $R$-wave progression. ST-Tpathology includes ECG with ST-elevation, ST-depression or T-wave inversion. PAC:

premature atrial contraction, PVC: premature ventricular contraction. $Q T C=$ Corrected $Q T$ time according to Bazett.

Biomarkers and organ dysfunction

Patients with prior MI pattern or ST-T-pathology at ICU admission had higher peak plasma values during ICU stay of troponin-I, NT-pro-BNP (N-terminal pro-Brain Natriuretic Peptide) and lactate compared to patients who had normal ECGs, but similar markers of inflammation (Table 4). More patients with prior MI pattern required treatment with vasoactive drugs compared to patients with normal ECG. Peak plasma 
levels of creatinine were higher in patients with prior MI pattern and higher but not statistically significant among patients with ST-T pathology compared to patients with normal ECG.

Table 4. Comparison of peak plasma laboratory values during intensive care unit stay and organ support between patients with normal ECG (reference) and ECG with prior myocardial infarction pattern or ST-T pathology respectively at intensive care unit admission.

\begin{tabular}{|c|c|c|c|c|c|}
\hline & $\begin{array}{l}\text { Normal ECG } \\
(n=51)\end{array}$ & $\begin{array}{l}\text { Prior MI pattern } \\
(\mathrm{n}=11)\end{array}$ & $\begin{array}{l}\mathrm{P}- \\
\text { value }\end{array}$ & $\begin{array}{l}\text { ST-T pathology } \\
(n=17)\end{array}$ & $\begin{array}{l}\mathrm{P} \text { - } \\
\text { value }\end{array}$ \\
\hline $\mathrm{CRP}$ & $281(166-378)$ & $294(251-375)$ & 0.34 & $261(222-352)$ & 0.99 \\
\hline [L-6 & $118(32-342)$ & 301 (181-369) & 0.11 & $260(121-458)$ & 0.52 \\
\hline Ferritin & $\begin{array}{l}2587(831- \\
3913)\end{array}$ & $1786(1160-3954)$ & 0.84 & $2253(821-5145)$ & 0.89 \\
\hline Troponin-I & $15(7-26)$ & $104(32-189)$ & 0.003 & $116(75-293)$ & $<0.001$ \\
\hline NT-pro-BNP & $555(274-1210)$ & $3390(529-5480)$ & 0.023 & $4810(3160-6090)$ & $<0.001$ \\
\hline D-dimer & $3.4(1.7-7.8)$ & $8.1(3.1-21)$ & 0.043 & $2.8(2.5-6.6)$ & 0.50 \\
\hline Lactate & $2.2(1.7-2.6)$ & $2.6(2.4-3.5)$ & 0.045 & $2.6(2.3-3.4)$ & 0.043 \\
\hline Creatinine & $95(79-142)$ & $128(100-218)$ & 0.047 & $121(97-215)$ & 0.057 \\
\hline $\begin{array}{l}\text { Lowest } \\
\mathrm{PaO}_{2} / \mathrm{FiO}_{2} \\
\text { ratio }\end{array}$ & $10.4(9.6-13.2)$ & $9.4(8.6-10.6)$ & 0.037 & $9.4(7.6-12.3)$ & 0.11 \\
\hline $\begin{array}{l}\text { Mechanical } \\
\text { ventilation }\end{array}$ & $29(57 \%)$ & $7(64 \%)$ & 0.68 & $10(59 \%)$ & 0.89 \\
\hline CRRT & $6(12 \%)$ & $2(18 \%)$ & 0.57 & $3(18 \%)$ & 0.54 \\
\hline $\begin{array}{l}\text { Vasoactive } \\
\text { treatment }\end{array}$ & $28(55 \%)$ & $10(91 \%)$ & 0.029 & $13(77 \%)$ & 0.12 \\
\hline
\end{tabular}

Data are presented as median (interquartile range) or number (percentages). MannWhitney U-test was used to compare continuous variables and $c h i^{2}$-test was used to compare categorical variables between patients with normal ECG and prior MI pattern and 
ST-T pathology. MI: myocardial infarction, CRP: C-reactive protein, IL-6: Interleukin 6, NTpro-BNP: N-Terminal pro brain natriuretic peptide, CRRT: Continuous renal replacement therapy. Laboratory reference ranges: $C R P<5 \mathrm{mg} / \mathrm{L}$; $I L-6<7,0 \mathrm{ng} / \mathrm{L}$; Ferritin male patients 25-310 $\mathrm{gg} / \mathrm{L}$, female patients 10-155 $\mu \mathrm{g} / \mathrm{L}$ (non-age-adjusted); Troponin I male patients <35 ng/L, female patients <16 ng/L; NT-pro-BNP male patients <230 ng/L, female patients <330 ng/L (non-age-adjusted); D-dimer <0.50 mg/L (non-age-adjusted); Lactate 0.5-1.6 mmol/L; Creatinine male patients 60-105 $\mu \mathrm{mol} / \mathrm{L}$, female patients 45-90 $\mu \mathrm{mol} / \mathrm{L}$;

\section{Discussion}

In this cohort study of 80 critically ill COVID-19 patients, several ECG pathologies were associated with death in the univariate analysis, including both prior MI pattern and ST-T pathology. An ECG consistent with prior MI pattern was associated with death in multivariate analysis adjusting for SAPS 3 . Both chronic and acute ECG pathology at ICU admission was associated with higher peak values of biomarkers of cardiac strain and damage, lactate and more frequent requirement for vasoactive treatment. This indicates that ECG at ICU admission may be an important prognostic tool in COVID-19.

Similar to our study, a cohort study of 756 patients with COVID-19 found that prior MI pattern and T-wave inversion at hospital admission were associated with death while sinus tachycardia was not ${ }^{21}$. Further, patients with ST-T pathology at hospital admission have a higher risk of developing more severe disease

22. In one study of 850 patients with ECG recorded at presentation to the emergency department, and another study of 269 patients that analysed ECG at hospital admission and the seventh day of hospitalization found that ST-T-pathology were predictive of death and invasive ventilation ${ }^{23,33}$. RBBB ${ }^{21}$, $\mathrm{AF}^{23}$, and $\mathrm{LVH}^{33}$ at hospital admission also have been reported to indicate higher risk of death in patients with COVID-19. These abnormalities were uncommon in our study and therefore lacked sufficient statistical power for analysis. Contrary to our findings, a study describing ECG findings at hospital admission in 431 patients who later died or underwent invasive ventilation reported abnormal ECG in 93\% of patients, a high prevalence of AF $(22 \%)$ and signs of right ventricular strain $(30 \%)^{24}$. In their cohort, patients were older (74 vs 61 years) and had higher over-all mortality (46\% vs $28 \%$ ) compared to our study, and they did not report the proportion of patients who were not eligible for ICU admission which may account for some of the differences between our study and theirs.

Both ECG pathology and elevated troponin have previously been associated with death ${ }^{9}$. There are several plausible explanations why severely ill COVID-19 patients develop ECG abnormalities and myocardial damage. Patients with pre-existing cardiovascular disease are more prone to develop secondary myocardial ischemia due to non-cardiac conditions ${ }^{34}$ such as hypoxia ${ }^{35}$. Consistent with this, we found that abnormalities associated with prior MI was associated with death and developed higher peak troponin-I and NT-pro-BNP values compared to patients with normal ECG. Patients with ST-T

Page $11 / 20$ 
pathology in our study also had higher odds of death and developed higher peak values of cardiac biomarkers compared to patients with normal ECG, which may be caused by several different pathophysiological mechanisms, such as ischemia due to pre-existing coronary stenosis with oxygen supply-demand mismatch ${ }^{34}$, acute coronary syndrome due to plaque rupture secondary ${ }^{19}$, myocardial microthrombi due to complement activation ${ }^{36}$ or myocarditis ${ }^{37}$. T-wave inversion, present in $16 \%$ of our cohort, may be present in up to $57 \%$ of patients with myocarditis ${ }^{38}$. In a study of unselected patients recently recovered from COVID-19, $60 \%$ of patients had finding consistent with myocardial inflammation on magnetic resonance imaging ${ }^{13}$. Myocarditis may be non-viral ${ }^{37}$, as a part of the hyperinflammatory response reported in COVID-19, but also due to direct viral infiltration in myocardial cells ${ }^{12,39,40}$.

Although patients with COVID-19 have high risk of pulmonary embolism ${ }^{41}$ and $11 \%$ of the patients in our cohort were diagnosed with pulmonary embolism, none of them had an ECG consistent with right ventricular strain. In a case series of 15 hospitalized patients with confirmed COVID-19 and pulmonary embolism, 33\% had right ventricular strain pattern on ECG while two-thirds had non-specific ECG findings, such as sinus tachycardia ${ }^{42}$. The absence of right ventricular strain pattern in our study could simply be due to the absence of pulmonary embolism at the time of the ECG-recording. However, critically ill patients with COVID-19 related pulmonary embolism may also have less clot burden ${ }^{43}$ compared to a general ICU population with pulmonary embolism, and right ventricular strain pattern may therefore not manifest on the ECG. Further, the incidence of pulmonary embolism was lower in our cohort than in other studies $^{44}$, possibly due to a higher dose low molecular weight heparin thromboprophylaxis at our ICU.

In a previous study, patients with an abnormal ECG developed higher peak plasma creatinine and had a higher incidence of continuous renal replacement therapy compared to patients with normal ECG ${ }^{45}$. In our study, peak plasma creatinine was similarly higher in patients with prior MI pattern compared to those with normal ECG. Patients with ST-T pathology also developed higher peak plasma creatinine values compared to patients with normal ECG, but this finding was only borderline significant, likely due to low statistical power. Kidney injury in COVID-19 is likely multifactorial and may be caused by several mechanisms, in part common to those responsible for cardiac injury, including both direct viral pathophysiological effects, systemic inflammation, hypovolemia and cardiopulmonary instability related to the degree of illness severity $2,34,46$. Pre-existing cardiovascular risk factors are frequent in COVID-19 patients ${ }^{5}$ and may further contribute to the development of simultaneous cardiac and renal dysfunction.

Contrary to previous studies, where immune dysregulation has been proposed as a major mechanism for cardiac injury in COVID- $19^{3}$ and cardiac biomarkers have been positively associated with inflammatory biomarkers ${ }^{47,48}$, we found no statistically difference in CRP, ferritin and IL-6, between patients with prior MI pattern or ST-T pathology compared to patients with normal ECG in our study. Patients admitted to the ICU may represent a cohort of patients with severe inflammatory response regardless of myocardial injury which could explain the lack of difference in our study. Pathological ECG changes may thus not primarily be caused by more severe inflammation, but rather similar levels of inflammation causing ECG abnormalities and cardiac injury primarily in patients with pre-existing cardiac disease. 
Strengths of this study included that ECG interpretation was conducted according to pre-specified criteria by two independent physicians blinded to patient outcomes. The study was conducted at a large tertiary referral centre with a large catchment area and all inhabitants in Sweden are covered by the public health insurance increasing generalizability of our study. Further, no patients were lost to follow up and there was minimal missing data.

There are also limitations of this study. The single centre design reduces generalizability and the small sample size hampers statistical power, especially in the multivariate analysis where only additional adjustment for SAPS 3 was feasible. Several patients did not have an ECG recorded at ICU admission, which may have led to selection bias if patients with pre-existing comorbidities or more severe disease were more likely to have ECG recorded. Even so, this study contains important new information for bedside clinicians and future studies. If confirmed, ECG findings presented herein may be used in prognostic tools for severe COVID-19 and the apparent lack of association between pathological ECG and inflammatory markers may further the understanding how COVID-19 affects the cardiovascular system.

\section{Conclusion}

ECG indicative of both chronic and acute cardiac conditions at ICU admission due to severe COVID-19 were associated with higher mortality and higher levels of cardiac biomarkers. ECG is an invaluable lowrisk investigation in a range of clinical scenarios. Our study suggests that an ECG provides important prognostic information in severe COVID-19 and should be considered in all critically ill COVID-19 patients.

\section{Declarations}

\section{Ethics approval and consent to participate}

The protocol was approved by the National Ethical Review Agency, Uppsala, Sweden (EPM; 2020-01623), and registered at ClinicalTrials (NCT04316884). Written informed consent was obtained from all participants or next of kin if the patient was unable to give consent.

\section{Consent for publication}

Not applicable

\section{Availability of data and materials}

Data is available from the corresponding author at reasonable request as detailed at https://doi.org/10.17044/scilifelab.14229410.v1.

\section{Funding}


The study was funded by the SciLifeLab/KAW national COVID-19 research program project grant to MH (KAW 2020.0182), the Swedish Research Council grant to RF (2014-02569 and 2014-07606).

\section{Authors' contributions}

MH conceived the study. JR, MN, MH, AM, ML and RF contributed to the design of the study. JR, MH, MH, $\mathrm{ML}, \mathrm{KS}$, and RF collected patient data. JR and MN performed ECG analysis. JR and KS performed data analysis. The first draft of the manuscript was written by JR. All authors commented on previous versions of the manuscript. All authors read and approved the final manuscript for publication.

\section{Acknowledgement}

The authors thank Elin Söderman, Joanna Wessbergh, Labolina Spång, Erik Danielsson and Philip Karlsson for excellent technical and administrative assistance. We also thank the collaborators of the Uppsala Intensive Care COVID-19 research group:

Tomas Luther, Sara Bülow Anderberg, Anna Gradin, Sara Galien, Sten Rubertsson and Katja Hanslin.

\section{Declaration of interests}

The authors declare that they have no conflict of interest.

\section{References}

1. Huang C, Wang Y, Li X, et al. Clinical features of patients infected with 2019 novel coronavirus in Wuhan, China. Lancet Lond Engl 2020; 395: 497-506.

2. Nadim MK, Forni LG, Mehta RL, et al. COVID-19-associated acute kidney injury: consensus report of the 25th Acute Disease Quality Initiative (ADQI) Workgroup. Nat Rev Nephrol 2020; 16: 747-764.

3. Zheng Y-Y, Ma Y-T, Zhang J-Y, et al. COVID-19 and the cardiovascular system. Nat Rev Cardio/2020; 17: $259-260$.

4. Wang D, Hu B, Hu C, et al. Clinical Characteristics of 138 Hospitalized Patients With 2019 Novel Coronavirus-Infected Pneumonia in Wuhan, China. JAMA 2020; 323: 1061-1069.

5. Richardson S, Hirsch JS, Narasimhan M, et al. Presenting Characteristics, Comorbidities, and Outcomes Among 5700 Patients Hospitalized With COVID-19 in the New York City Area. JAMA. Epub ahead of print 22 April 2020. DOI: 10.1001/jama.2020.6775.

6. Shi S, Qin M, Shen B, et al. Association of Cardiac Injury With Mortality in Hospitalized Patients With COVID-19 in Wuhan, China. JAMA Cardiol. Epub ahead of print 25 March 2020. DOI:

10.1001/jamacardio.2020.0950. 
7. Guo T, Fan Y, Chen M, et al. Cardiovascular Implications of Fatal Outcomes of Patients With Coronavirus Disease 2019 (COVID-19). JAMA Cardiol. Epub ahead of print 27 March 2020. DOI: 10.1001/jamacardio.2020.1017.

8. Lippi G, Lavie CJ, Sanchis-Gomar F. Cardiac troponin I in patients with coronavirus disease 2019 (COVID-19): Evidence from a meta-analysis. Prog Cardiovasc Dis. Epub ahead of print 10 March 2020. DOI: 10.1016/j.pcad.2020.03.001.

9. Poterucha Timothy J., Elias Pierre, Jain Sneha S., et al. Admission Cardiac Diagnostic Testing with Electrocardiography and Troponin Measurement Prognosticates Increased 30-Day Mortality in COVID-19. J Am Heart Assoc 2021; 10: e018476.

10. Maeda T, Obata R, Rizk D, et al. Cardiac Injury and Outcomes of Patients with COVID-19 in New York City. Heart Lung Circ. Epub ahead of print 23 November 2020. DOI: 10.1016/j.hlc.2020.10.025.

11. Lala A, Johnson KW, Januzzi JL, et al. Prevalence and Impact of Myocardial Injury in Patients Hospitalized With COVID-19 Infection. J Am Coll Cardiol 2020; 76: 533-546.

12. Xu Z, Shi L, Wang Y, et al. Pathological findings of COVID-19 associated with acute respiratory distress syndrome. Lancet Respir Med 2020; 8: 420-422.

13. Puntmann VO, Carerj ML, Wieters I, et al. Outcomes of Cardiovascular Magnetic Resonance Imaging in Patients Recently Recovered From Coronavirus Disease 2019 (COVID-19). JAMA Cardiol. DOI: 10.1001/jamacardio.2020.3557.

14. Meyer P, Degrauwe S, Van Delden C, et al. Typical takotsubo syndrome triggered by SARS-CoV-2 infection. Eur Heart J 2020; 41: 1860.

15. Einthoven W, de Lint K. Ueber das normale menschliche Elektrokardiogramm und über die capillarelektrometrische Untersuchung einiger Herzkranken. Arch Für Gesamte Physiol Menschen Tiere 1900; 80: 139-160.

16. Goldstein B. Intensive Care Unit ECG Monitoring. Card Electrophysiol Rev 1997; 1: 308-310.

17. He J, Wu B, Chen Y, et al. Characteristic Electrocardiographic Manifestations in Patients With COVID19. Can J Cardiol. Epub ahead of print 29 March 2020. DOI: 10.1016/j.cjca.2020.03.028.

18. Doyen D, Moceri P, Ducreux D, et al. Myocarditis in a patient with COVID-19: a cause of raised troponin and ECG changes. The Lancet, 0. Epub ahead of print 23 April 2020. DOI: 10.1016/S01406736(20)30912-0.

19. Bangalore S, Sharma A, Slotwiner A, et al. ST-Segment Elevation in Patients with Covid-19 - A Case Series. N Engl J Med 2020; 0: null. 
20. Mp A, Ey W, Mp W, et al. Clinical and cardiac characteristics of COVID-19 mortalities in a diverse New York City Cohort. Journal of cardiovascular electrophysiology. Epub ahead of print 10 June 2020. DOI: $10.1111 /$ jce.14772.

21. Sa M, P G, U K, et al. Electrocardiographic Findings in Coronavirus Disease-19: Insights on Mortality and Underlying Myocardial Processes. Journal of cardiac failure; 26. Epub ahead of print July 2020. DOI: 10.1016/j.cardfail.2020.06.005.

22. Barman HA, Atici A, Alici G, et al. The effect of the severity COVID-19 infection on electrocardiography. Am J Emerg Med; 0. Epub ahead of print 7 October 2020. DOI: 10.1016/j.ajem.2020.10.005.

23. Elias P, Poterucha TJ, Jain SS, et al. The Prognostic Value of Electrocardiogram at Presentation to Emergency Department in Patients With COVID-19. Mayo Clin Proc 2020; 95: 2099-2109.

24. Bertini M, Ferrari R, Guardigli G, et al. Electrocardiographic features of 431 consecutive, critically ill COVID-19 patients: an insight into the mechanisms of cardiac involvement. Europace. Epub ahead of print 18 September 2020. DOI: 10.1093/europace/euaa258.

25. Luther T, Bülow-Anderberg S, Larsson A, et al. COVID-19 patients in intensive care develop predominantly oliguric acute kidney injury. Acta Anaesthesio/ Scand, n/a. DOI: https://doi.org/10.1111/aas.13746.

26. Mason JW, Hancock EW, Gettes LS. Recommendations for the Standardization and Interpretation of the Electrocardiogram: Part II: Electrocardiography Diagnostic Statement List A Scientific Statement From the American Heart Association Electrocardiography and Arrhythmias Committee, Council on Clinical Cardiology; the American College of Cardiology Foundation; and the Heart Rhythm Society Endorsed by the International Society for Computerized Electrocardiology. J Am Coll Cardiol 2007; 49: 1128-1135.

27. Bazett HC. An Analysis of the Time-Relations of Electrocardiograms. Ann Noninvasive Electrocardiol 1997; 2: 177-194.

28. Thygesen K, Alpert JS, Jaffe AS, et al. Fourth universal definition of myocardial infarction (2018). Eur Heart J 2019; 40: 237-269.

29. Zema MJ, Collins M, Alonso DR, et al. Electrocardiographic Poor R-Wave Progression: Correlation with Postmortem Findings. CHEST 1981; 79: 195-200.

30. Anttila IJT, Nikus KC, Lehtimaki T, et al. Relation of poor R-wave progression to risk of cardiovascular mortality. Eur Heart J; 34. Epub ahead of print 1 August 2013. DOI: 10.1093/eurheartj/eht308.P1540.

31. Rautaharju PM, Surawicz B, Gettes LS. AHA/ACCF/HRS Recommendations for the Standardization and Interpretation of the Electrocardiogram: Part IV: The ST Segment, T and U Waves, and the QT Interval A Scientific Statement From the American Heart Association Electrocardiography and Arrhythmias 
Committee, Council on Clinical Cardiology; the American College of Cardiology Foundation; and the Heart Rhythm Society Endorsed by the International Society for Computerized Electrocardiology. J Am Coll Cardio/ 2009; 53: 982-991.

32. Moreno RP, Metnitz PGH, Almeida E, et al. SAPS 3-From evaluation of the patient to evaluation of the intensive care unit. Part 2: Development of a prognostic model for hospital mortality at ICU admission. Intensive Care Med 2005; 31: 1345-1355.

33. Giustino G, Croft LB, Stefanini GG, et al. Characterization of Myocardial Injury in Patients With COVID-19. J Am Coll Cardiol 2020; 76: 2043-2055.

34. Defilippis Andrew P., Chapman Andrew R., Mills Nicholas L., et al. Assessment and Treatment of Patients With Type 2 Myocardial Infarction and Acute Nonischemic Myocardial Injury. Circulation 2019; 140: $1661-1678$.

35. Bavishi C, Bonow RO, Trivedi V, et al. Special Article - Acute myocardial injury in patients hospitalized with COVID-19 infection: A review. Prog Cardiovasc Dis 2020; 63: 682-689.

36. Pellegrini Dario, Kawakami Rika, Guagliumi Giulio, et al. Microthrombi as a Major Cause of Cardiac Injury in COVID-19. Circulation 2021; 143: 1031-1042.

37. Js H, Ch S, My C, et al. Coronavirus-induced myocarditis: A meta-summary of cases. Heart \& lung: the journal of critical care, 49. Epub ahead of print December 2020. DOI: 10.1016/j.hrtlng.2020.08.013.

38. Buttà C, Zappia L, Laterra G, et al. Diagnostic and prognostic role of electrocardiogram in acute myocarditis: A comprehensive review. Ann Noninvasive Electrocardio/ 2020; 25: e12726.

39. Tavazzi G, Pellegrini C, Maurelli M, et al. Myocardial localization of coronavirus in COVID-19 cardiogenic shock. Eur J Heart Fail; n/a. DOI: 10.1002/ejhf.1828.

40. Puelles VG, Lütgehetmann M, Lindenmeyer MT, et al. Multiorgan and Renal Tropism of SARS-CoV-2. N Engl J Med. Epub ahead of print 13 May 2020. DOI: 10.1056/NEJMc2011400.

41. Malas MB, Naazie IN, Elsayed N, et al. Thromboembolism risk of COVID-19 is high and associated with a higher risk of mortality: A systematic review and meta-analysis. EClinicalMedicine, 29. Epub ahead of print 1 December 2020. DOI: 10.1016/j.eclinm.2020.100639.

42. Kho J, loannou A, Van den Abbeele K, et al. Pulmonary embolism in COVID-19: Clinical characteristics and cardiac implications. Am J Emerg Med 2020; 38: 2142-2146.

43. Dam LF van, Kroft LJM, Wal LI van der, et al. Clinical and computed tomography characteristics of COVID-19 associated acute pulmonary embolism: A different phenotype of thrombotic disease? Thromb Res 2020; 193: 86-89. 
44. Longchamp G, Manzocchi-Besson S, Longchamp A, et al. Proximal deep vein thrombosis and pulmonary embolism in COVID-19 patients: a systematic review and meta-analysis. Thromb $J$ 2021; 19 : 15.

45. Bergamaschi L, D'Angelo EC, Paolisso $P$, et al. The value of ECG changes in risk stratification of COVID-19 patients. Ann Noninvasive Electrocardiol; n/a: e12815.

46. Hultstöm M, von Seth M, Frithiof R. Hyperreninemia and low total body water may contribute to acute kidney injury in corona virus disease 2019 patients in intensive care. $J$ Hypertens. Epub ahead of print 28 May 2020. DOI: 10.1097/HJH.0000000000002531.

47. Zhou F, Yu T, Du R, et al. Clinical course and risk factors for mortality of adult inpatients with COVID19 in Wuhan, China: a retrospective cohort study. The Lancet 2020; 395: 1054-1062.

48. Li Dongze, Chen You, Jia Yu, et al. SARS-CoV-2-Induced Immune Dysregulation and Myocardial Injury Risk in China. Circ Res 2020; 127: 397-399.

\section{Figures}




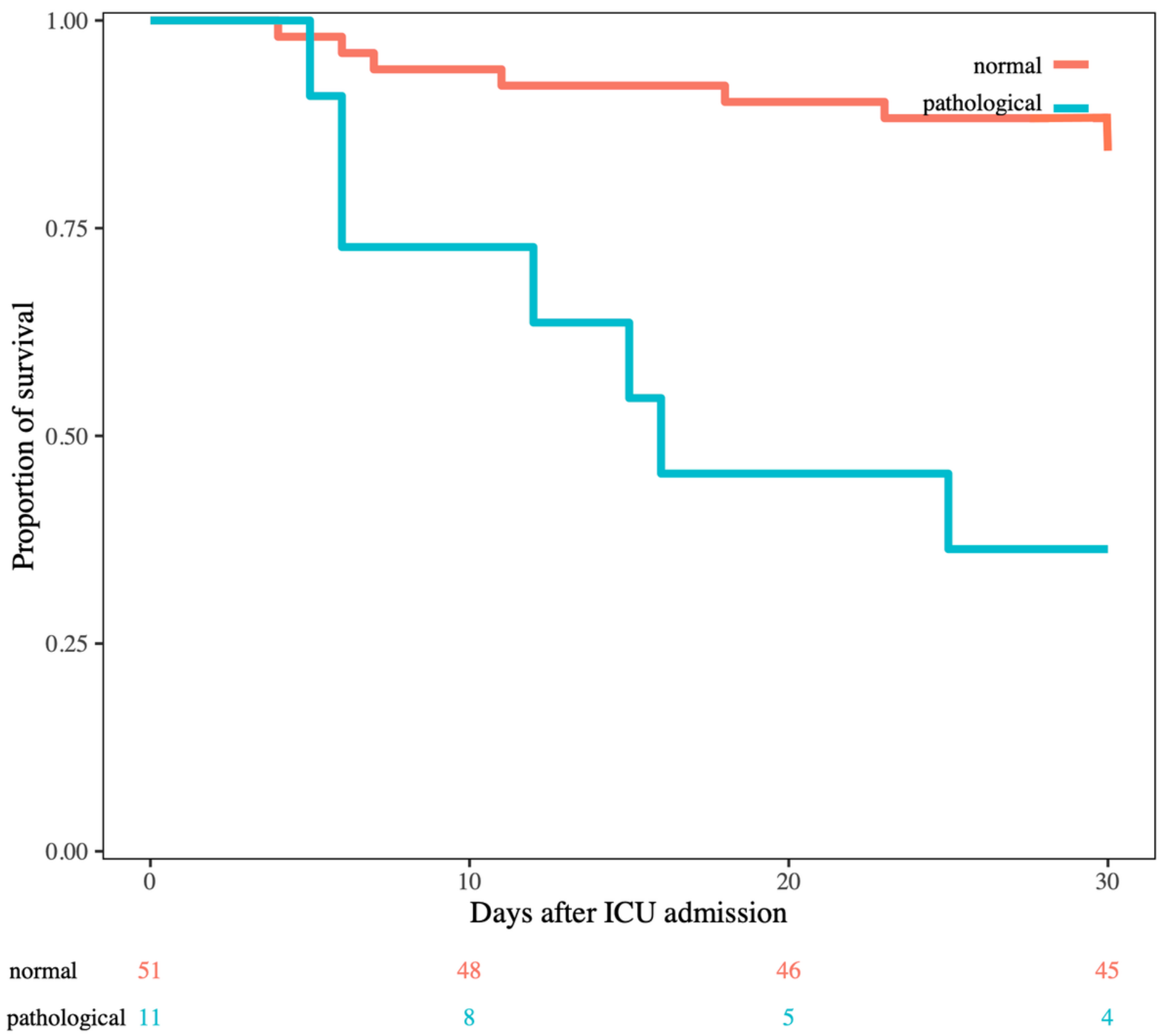

Figure 1

Kaplan-Meier survival analysis of patients with normal ECG and patients with prior myocardial infarction pattern, $\mathrm{P}<0.001$. 


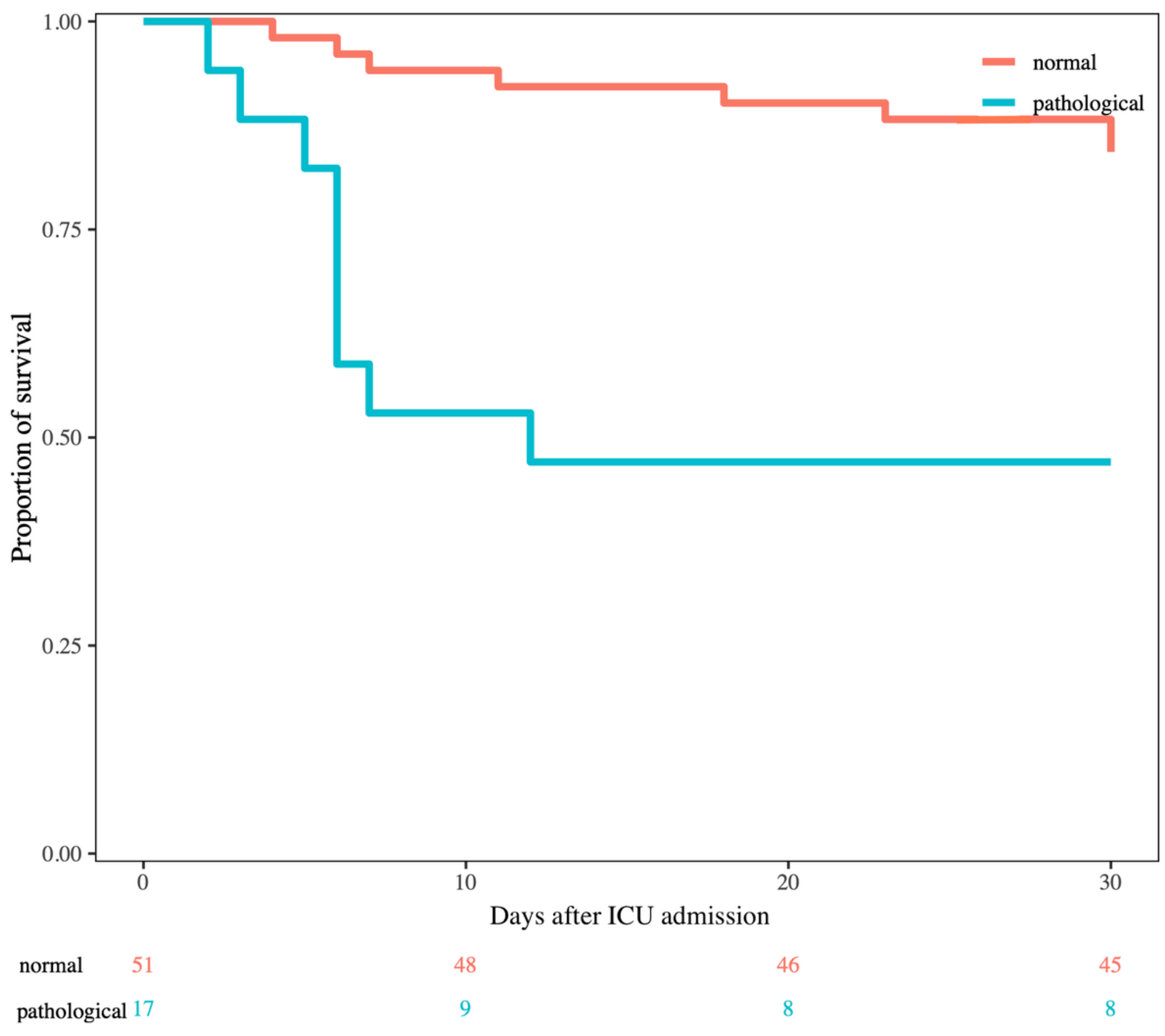

Figure 2

Kaplan-Meier survival analysis of patients with normal ECG and patients with ST-T pathology (STelevation, ST-depression or T-wave inversion), $\mathrm{P}<0.001$. 